Reprinted with permission from: Weed Science. 1989. 37(2):167-174.

Published and copyrighted by: Weed Science Society of America. http://www.wssa.net

\title{
Picloram release from leafy spurge (Euphorbia esula) roots in the field ${ }^{1}$
}

\author{
MICHAEL V. HICKMAN, CALVIN G. MESSERSMITH, and RODNEY G. LYM \\ The authors are former Grad. Res. Asst., Prof., and Assoc. Prof., Crop and Weed Sci. Dep., respectively, N.D. State \\ Univ., Fargo, ND 58105. Present address of the senior author is: U.S. Dep. Agric., Agric. Res. Serv., P.O. Box 267, \\ Weslaco, TX 78596.
}

\begin{abstract}
:
Picloram release by leafy spurge roots, as affected by picloram rate, plant growth stage, and time intervals after treatment, was quantified under field conditions. Picloram was pipe-wick applied to leafy spurge in the vegetative, flowering, and seed-filling growth stages. Percent leafy spurge control was evaluated and picloram residues were determined in soil samples from 0 - to 13-, 13- to 26-, and 26- to 39-cm depths taken 1, 2, and 3 weeks after treatment. Leafy spurge was controlled (frequently $>85 \%$ ) by all picloram concentrations applied, although control tended to increase as solution concentration increased. Picloram release from roots was greater from plants treated in the flowering and seed-filling stages than from plants in the vegetative stage. Picloram release from roots generally was correlated with application rate, averaging 490, 820, and 1420 ppbw in soil for the 30,60 , and $120 \mathrm{~g}$ ae/L application rates, respectively. Picloram release from roots occurred rapidly with $86 \%$ of the picloram detected in the 0 - to $13-\mathrm{cm}$ soil depth present by 1 week after treatment. Picloram was detected at all soil depths sampled, but over $84 \%$ was in the upper $13 \mathrm{~cm}$ and $8 \%$ was in both the 13- to 26- and 26- to $39-\mathrm{cm}$ depths. Leafy spurge shoots emerged through a 7.5- and 15-cm depth of picloram-treated soil at concentrations up to 1000 ppbw within 14 to 21 days after the untreated control. Picloram soil residue had little effect on leafy spurge root growth.
\end{abstract}

\footnotetext{
${ }^{1}$ Received for publication June 6, 1988, and in revised form December 16, 1988. Published with approval of the Director, Agric. Exp. Stn., N.D. State Univ. as J. Art. No. 1679.
} 


\section{Nomenclature:}

Picloram, 4-amino-3,5,6-trichloro-2-pyridinecarboxylic acid; leafy spurge, Euphorbia esula L. \#² EPHES.

\section{Introduction}

Leafy spurge is an introduced, herbaceous, perennial weed that infests range, pasture, and noncrop areas throughout the north-central United States and south-central Canada. Leafy spurge control has been attempted through cultural and mechanical means including cropping, mowing, grazing, and tillage. These attempts have met with limited success. Herbicide treatment is the most effective method for long-term control of leafy spurge.

Herbicides that control leafy spurge include 2,4-D [(2,4dichlorophenoxy) acetic acid], dicamba (3,6-dichloro-2-methoxybenzoic acid), picloram, and glyphosate [N-(phosphonomethyl)glycine]. Picloram is the most effective chemical for most range and pasture applications, although 2,4-D and dicamba may be used also. Glyphosate is nonselective which makes it useful for weed control in shelterbelts but not for range and pastureland.

These herbicides only control the upper portion of leafy spurge roots. This is due to limited translocation and perhaps herbicide exudation by roots. The release of herbicides from plant roots following foliar application has been documented $(2,3,6,10,11,16)$. This release may be a tolerance mechanism, as with 2,4-D release by jimsonweed ( $D a$ tura stramonium L.) (6). Up to $85 \%$ of the 2,4 -D translocated to the root zone of small leafy spurge cuttings was released into the nutrient solution surrounding the roots (11). Picloram exuded from roots of 'Black Valentine' beans (Phaseolus vulgaris L.) within 24 hours of foliar application (10). As much as $7 \%$ of the picloram absorbed by leafy spurge foliage was released from the roots within 72 hours of treatment (2).

The purpose of this research was to quantify picloram released by leafy spurge roots and its effect on root growth under field conditions as affected by herbicide application rate, plant growth stage, and various time intervals after treatment.

\section{Materials and methods}

\section{Field exudation}

Experiments were established in mature stands of leafy spurge at Hunter and Sheldon, ND, in May 1984 and were repeated in 1985. The experimental design was a randomized

\footnotetext{
${ }^{2}$ Letters following this \# symbol are a WSSA-approved computer code from Composite List of Weeds, Weed Sci. 32 , Suppl. 2. Available from WSSA, 309 West Clark Street, Champaign, IL 61820.
} 
complete block with four replications and 3- by 9-m plots. Treatments consisted of picloram concentrations of 30,60 , and $120 \mathrm{~g}$ ae/L applied to leafy spurge in the vegetative, flowering, and seed-filling growth stages. A pipe-wick applicator (15) was used to minimize herbicide contact with the soil. The herbicide solutions were applied with two passes in opposite directions.

Soil samples were taken 1, 2, and 3 weeks after herbicide application by subsampling from two locations within each plot. The subsamples were obtained by digging a hole with a 46-cm-long garden spade, then cutting a 3-cm-thick slice from the sidewall, and dividing each subsample into the 0 - to 13-, 13- to 26-, and 26- to 39-cm depths. The subsamples were combined for each depth by location to give a total of three samples/plot for each sampling date. The soil samples were air dried, passed through a 5-mm-mesh screen to remove stones and plant material, and thoroughly mixed. Following screening, 30- and 500-g samples were stored dry at room temperature until used in chemical extractions and bioassays, respectively.

All experiments were evaluated visually for percent leafy spurge control, based on reduction of leafy spurge density, approximately 1 year after application.

\section{Soil bioassay}

Picloram soil concentrations in 13- to 26 and 26- to 39-cm depths were estimated using a sunflower (Helianthus annuus L.) bioassay. Untreated soil was sampled as previously described and used for determination of the standard curve. The soil was placed in paper bags and treated with $10 \mathrm{ml}$ of solution to give nine picloram concentrations from 0 to $500 \mathrm{ppbw}$ (air-dry basis). Four bags of treated soil/concentration were air dried for 24 hours before being thoroughly mixed. Soil was transferred into 10 - by 10 - by 6 -cm paperlined plastic pots. Each pot was placed into an individual styrofoam tray to permit surface and subirrigation and prevent picloram loss by leaching.

The field and standard curve samples were arranged in the greenhouse as a completely random design for each sampling depth. Each pot was seeded with eight sunflower seeds, and the soil was covered with approximately $2 \mathrm{~cm}$ of vermiculite and watered to field capacity. After emergence, the sunflowers were thinned to four plants/pot. The plants were grown for 21 to 28 days (16 hours a day/8 hours a night) with weekly rerandomization of the pots to minimize the effects of greenhouse environment. Pots were alternately surfaced and subirrigated to near field capacity as needed.

Total shoot dry weight was determined by oven drying at $60^{\circ} \mathrm{C}$ for 36 hours. Picloram residues in the soil were calculated from a regression equation generated from the dry weights of the standard curve plants. Coefficients of determination $\left(\mathrm{r}^{2}\right)$ of the standard curves averaged $0.94(\mathrm{P} \leq 0.05)$.

\section{Chemical extractions}

The picloram concentration in soil samples from the 0 - to $13-\mathrm{cm}$ depth was determined by chemical extraction and high-pressure liquid chromatography because the picloram concentrations in the soil exceeded the upper detection limit of the sunflower 
bioassay. The picloram extraction procedure described was adapted from several previously reported procedures $(1,7,18,19)$.

Picloram was extracted from $20 \mathrm{~g}$ of soil with $30 \mathrm{ml}$ of extracting solution (acetonitrile:ammonium hydroxide:water, $70: 18: 12, \mathrm{v} / \mathrm{v} / \mathrm{v}$ ) in a $125-\mathrm{ml}$ flask. The stoppered flasks were shaken by mechanical shaker for 30 minutes and were allowed to stand at room temperature for 18 hours before being shaken an additional 30 minutes. The solution was vacuum filtered through Whatman No. 3 filter paper (pore size $=6 \mu \mathrm{m}$ ), and each flask was rinsed with approximately $5 \mathrm{ml}$ of extracting solution, which also was filtered. The soil and filter paper were discarded.

The filtrate was evaporated in a rotary evaporator to remove the acetonitrile and ammonium hydroxide. Evaporation continued until no ammonia could be detected by smell. The remaining solution was centrifuged for 10 minutes at 10,000 g. The supernatant was collected and filtered (pore size $=0.2 \mu \mathrm{m}$ ) into a volumetric flask. The volume was adjusted to $50 \mathrm{ml}$ by adding $5 \%$ aqueous sodium carbonate $(\mathrm{w} / \mathrm{v})$, which resulted in a $\mathrm{pH}$ of approximately 11 . The solution was transferred into a $250-\mathrm{ml}$ separatory funnel and was shaken 1 minute to ensure complete mixing.

Hexane $(10 \mathrm{ml})$ was added to remove organic contaminants, and the mixture was shaken for 2 minutes and allowed to stand until phase separation was complete. The aqueous phase was drawn off and acidified to approximately $\mathrm{pH} 2$ by adding $6 \mathrm{ml}$ concentrated sulfuric acid. The hexane fraction was discarded. The acidified fraction was returned to the separatory funnel and $1 \mathrm{ml}$ saturated potassium permanganate was added. The mixture was allowed to stand for 5 minutes before the reaction was stopped by dropwise addition of $5 \mathrm{M}$ sodium bisulfite until the solution became colorless.

Picloram was extracted by partitioning with $10 \mathrm{ml}$ of dichloromethane after 3 minutes of shaking. The partitioning was repeated and the aqueous fraction was discarded. The two dichloromethane fractions were combined in a $250-\mathrm{ml}$ round-bottom boiling flask and were evaporated to dryness under vacuum at $30^{\circ} \mathrm{C}$. The picloram was resolubilized from the evaporation flask in $1.5 \mathrm{ml}$ of acetonitrile-water $(60: 40, \mathrm{v} / \mathrm{v})$ and analyzed by HPLC.

Separations were made by high-pressure liquid chromatography using a C-18 reversephase column with a two-part solvent system; part ' $A$ ' was acetonitrile and water (80:20, $\mathrm{v} / \mathrm{v})$ and part ' $\mathrm{B}$ ' was water. The solvents were acidified by adding $1 \%(\mathrm{v} / \mathrm{v})$ acetic acid. Separations were made using a linear gradient elution going from 5\% ' $\mathrm{A}$ ' to $93.8 \%$ ' $\mathrm{A}$ ' in 20 minutes. Flow rate was $1 \mathrm{ml} /$ minute and column temperature was $25^{\circ} \mathrm{C}$.

The detector was a spectrophotometer operated at $254 \mathrm{~nm}$. The picloram detection limit was $<10 \mathrm{ppbw}$ by comparison to a standard curve. Retention time for picloram was approximately 9 minutes and was determined using standard solutions of technical grade picloram in water acidified with acetic acid. A standard curve was produced by treating 500 -g soil samples with picloram to give final picloram concentrations from 0 to 4000 ppbw. The treated standard curve samples were aged for approximately 30 days before extraction. Picloram concentrations in the field samples were calculated using a regression equation generated from the peak area of the standard curve samples $\left(r^{2}=0.96\right)$. 


\section{Root growth inhibition}

The concentration of picloram required to inhibit leafy spurge root bud growth was determined by excavating soil in established leafy spurge infestations and replacing it with picloram-treated soil. The time to shoot emergence and picloram concentration in soil at emergence were compared to untreated controls at two soil depths and four picloram concentrations. Soil was excavated 0 to 7.5 or 0 to $15 \mathrm{~cm}$ deep from 30 - by $30-\mathrm{cm}$ plots, replaced with soil containing 0 to 1000 ppbw technical picloram, and tamped firm. The experiments were established in a natural infestation near Fargo on May 7, 1985, and April 11, 1986, and in a 5-year-old stand established at the Fargo experiment station in 1985 only. There were four and six replications in 1985 and 1986, respectively, at each location, in a randomized complete block design.

The plots were evaluated twice weekly for leafy spurge shoot emergence. If the shoots did not emerge until the next growing season the days the soil was frozen were not considered in the time to shoot emergence. Following emergence, the soil around the stem was removed to verify that new growth came from roots below the treated area. Also, a soil sample was collected from 0 to 7.5 or 0 to $15 \mathrm{~cm}$, stored, and analyzed for picloram concentration using the sunflower bioassay as previously described.

\section{Data analysis}

The data gathered from field experiments conducted at Sheldon and Hunter, ND, in 1984 and 1985 were subjected to Bartlett's chi-square test for homogeneity of variance (8) and neither the original nor the arc sin transformed data could be combined. Therefore, results of evaluations for percent leafy spurge control and for picloram concentrations in soil from all sampling depths were treated as separate experiments for analysis and discussion. There were occasional interactions between factors but overall trends were the same and were averaged for discussion.

\section{Results and discussion}

\section{Leafy spurge control}

One year after treatment most picloram concentrations applied by pipe-wick controlled leafy spurge (frequently $>85 \%$ ), although the control tended to decrease as the solution concentration decreased (Table 1). These observations are consistent with an earlier report by Lym and Messersmith (12).

The leafy spurge was less susceptible to picloram in the vegetative growth stage than in the flowering or seed-filling stages in 1984 at both locations (Table 1). This observation agrees with previous research that found leafy spurge control was best when herbicides were applied at the early flowering growth stage (12). Results from 1985 were contrary to those of 1984 with similar control at all three growth stages at both locations.

There is no clear explanation for this inconsistency, although fluctuation in the environment may be an important factor. Ebke and McCarty (5) described variability in leafy 
spurge plants grown in a nursery at Lincoln, NE, both in many measured parameters from one season to the next and even within the same season. They observed variations in plants within the same growth tube. A high negative correlation between large fluctuations in total nonstructural carbohydrates in leafy spurge roots and environmental factors, especially temperature, was reported in North Dakota (31). These large fluctuations in physiological and morphological parameters demonstrate the inherent variability of leafy spurge.

\section{Release 0 to $13 \mathrm{~cm}$}

Picloram residues in soil from the 0 - to $13-\mathrm{cm}$ depth were greatest when plants were treated at the flowering stage in 1984 and at the seed-filling stage in 1985 (Table 2). Picloram release from roots of plants treated in the flowering growth stage in 1984 was three or more times greater than from plants treated in the vegetative or seed-filling growth stages at both locations. Release from roots of plants treated at the latter two growth stages in 1985 averaged two to three times greater than from plants treated at the vegetative growth stage at both locations.

Table 1. Leafy spurge control 12 months after treatment with picloram pipe-wick applied at three growth stages and three rates at Hunter and Sheldon, ND, in 1984 and 1985.

\begin{tabular}{|c|c|c|c|c|c|c|c|c|c|}
\hline \multirow[b]{3}{*}{ Rate } & \multirow[b]{3}{*}{ Year } & \multicolumn{8}{|c|}{ Control as affected by plant growth stage and location } \\
\hline & & \multicolumn{2}{|c|}{ Vegetative } & \multicolumn{2}{|c|}{ Flowering } & \multicolumn{2}{|c|}{ Seed-fill } & \multicolumn{2}{|c|}{ Mean } \\
\hline & & Sheldon & Hunter & Sheldon & Hunter & Sheldon & Hunter & Sheldon & Hunter \\
\hline \multicolumn{2}{|c|}{$(\mathrm{g} / \mathrm{L})$} & & & & & & & & \\
\hline \multirow[t]{2}{*}{30} & 1984 & 31 & 89 & 87 & 100 & 93 & 99 & 70 & 96 \\
\hline & 1985 & 93 & 88 & 96 & 65 & 100 & 84 & 96 & 79 \\
\hline \multirow[t]{2}{*}{60} & 1984 & 70 & 25 & 99 & 100 & 98 & 100 & 89 & 75 \\
\hline & 1985 & 95 & 98 & 100 & 84 & 100 & 91 & 98 & 91 \\
\hline \multirow[t]{2}{*}{120} & 1984 & 76 & 100 & 100 & 100 & 100 & 100 & 92 & 100 \\
\hline & 1985 & 100 & 97 & 100 & 89 & 100 & 82 & 100 & 89 \\
\hline \multicolumn{10}{|l|}{ Means: } \\
\hline \multirow[t]{2}{*}{ Stage } & 1984 & 59 & 71 & 95 & 100 & 97 & 100 & & \\
\hline & 1985 & 96 & 94 & 99 & 79 & 100 & 86 & & \\
\hline \multirow[t]{2}{*}{ Year } & 1984 & & & & & & & 84 & 90 \\
\hline & 1985 & & & & & & & 98 & 86 \\
\hline \multicolumn{10}{|c|}{$\begin{array}{l}\text { LSD (0.05) } 1984 \text { growth stage Sheldon }=12 ; \text { Hunter }=8 \\
\text { LSD (0.05) } 1984 \text { rate Sheldon = } 12 ; \text { Hunter }=8 \\
\text { LSD (0.05) } 1985 \text { growth stage Sheldon = NS; Hunter = NS } \\
\text { LSD (0.05) } 1985 \text { rate Sheldon - NS; Hunter = NS }\end{array}$} \\
\hline
\end{tabular}

${ }^{a}$ Estimates of percent leafy spurge control are based on visual evaluations compared to untreated controls.

The observed shift in highest release rates from plants treated in the flowering growth stage in 1984 to the seed-filling growth stage in 1985 may have been due to different environmental conditions between years. The experimental sites were dry in 1984, and leafy 
spurge matured rapidly. The 1985 growing season was more favorable for leafy spurge growth, and the plants remained vigorous through the seed-filling stage. The extended period of active growth in 1985 compared to 1984 may have allowed more time for herbicide translocation, resulting in greater release.

Leafy spurge plants in the flowering and seed-filling growth stages usually are larger and have more leaf and stem surface than vegetative plants. This difference in size likely would result in the largest plants receiving the highest rate of herbicide from the pipewick applicator. This difference in initial application rate may be an important factor accounting for the observed differences in control and picloram release from roots between growth stages.

Table 2. Picloram concentrations in soil from 0-to 13-cm depth at Sheldon and Hunter, ND, 1,2 , and 3 weeks after treatment at three rates on vegetative, flowering, and seed-filling leafy spurge in 1984 and $1985^{\mathrm{a}}$.

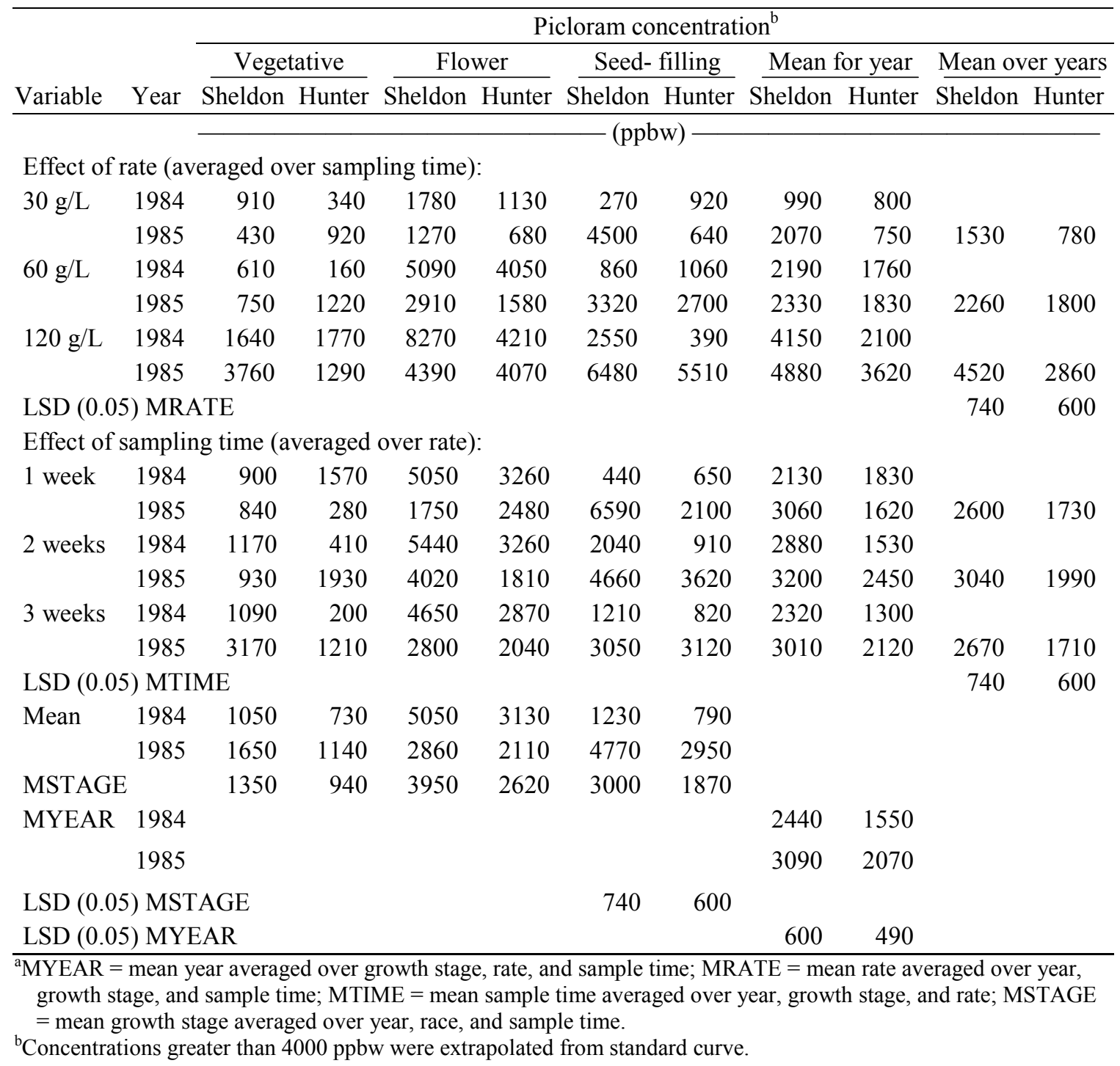


Picloram release from roots generally increased as the application rate increased at both locations and in both years (Table 2), except for treatments to vegetative plants in 1984 at both locations and for seed-filling plants in 1984 at Hunter and in 1985 at Sheldon. However, the only significant difference was for seed-filling plants at Sheldon in 1985.

Picloram release from roots essentially was complete by 1 week after application (Table 2). No differences in picloram residue were detected between samples taken 1, 2, and 3 weeks after treatment, except between 1 and 2 weeks at Sheldon in 1984 and at Hunter in 1985. However, release from roots tended to increase between the first and second weeks after application for three of the four location year combinations.

There were interactions between the year, application rate, plant growth stage, and sampling time at Sheldon. The inconsistency in response to treatment at differing application rates and plant growth stages apparently is responsible for most of this interaction.

\section{Release 13 to $26 \mathrm{~cm}$}

Picloram residues detected in soil in 1984 were greatest for plants treated in the vegetative growth stage at Sheldon and in the vegetative and flowering growth stages at Hunter (Table 3). In 1985, residues were greatest for plants treated in the seed-filling growth stage at Sheldon and in the flowering and seed-filling growth stages at Hunter.

As discussed previously, the shift in picloram release from roots to the treatments at later growth stages in 1985 versus 1984 may be due in part to better growing conditions in 1985 . The more favorable conditions resulted in leafy spurge plants that continued to grow and develop new leaves and vegetative branches even as they were setting seed. Larger, more robust plants probably would absorb and translocate more picloram resulting in more release from the roots at the later growth stages in 1985 than in 1984.

Residue levels in soil increased as the application rate increased at Sheldon in both years and at Hunter in 1985 (Table 3). The differences between the low and high residue levels were smaller at Sheldon in 1985 than in 1984, but the treatments had the same ranking order. Residue levels were similar following application of picloram at 30 or 60 $\mathrm{g} / \mathrm{L}$ at Hunter in 1984 , but increasing the application rate to $120 \mathrm{~g} / \mathrm{L}$ did result in higher soil residue levels.

Picloram residues in soil tended to increase with time after application for both locations and years, when treatments were averaged over plant growth stages (Table 3). Maximum soil residue levels, averaged over rates, generally were reached by 2 weeks after picloram application in 1984, and 3 weeks after application in 1985. 
Table 3. Picloram concentrations in soil from 13- to 26-cm depth at Sheldon and Hunter, ND, 1, 2, and 3 weeks after treatment at three rates on vegetative, flowering, and seed-filling leafy spurge in 1984 and $1985^{\circ}$.

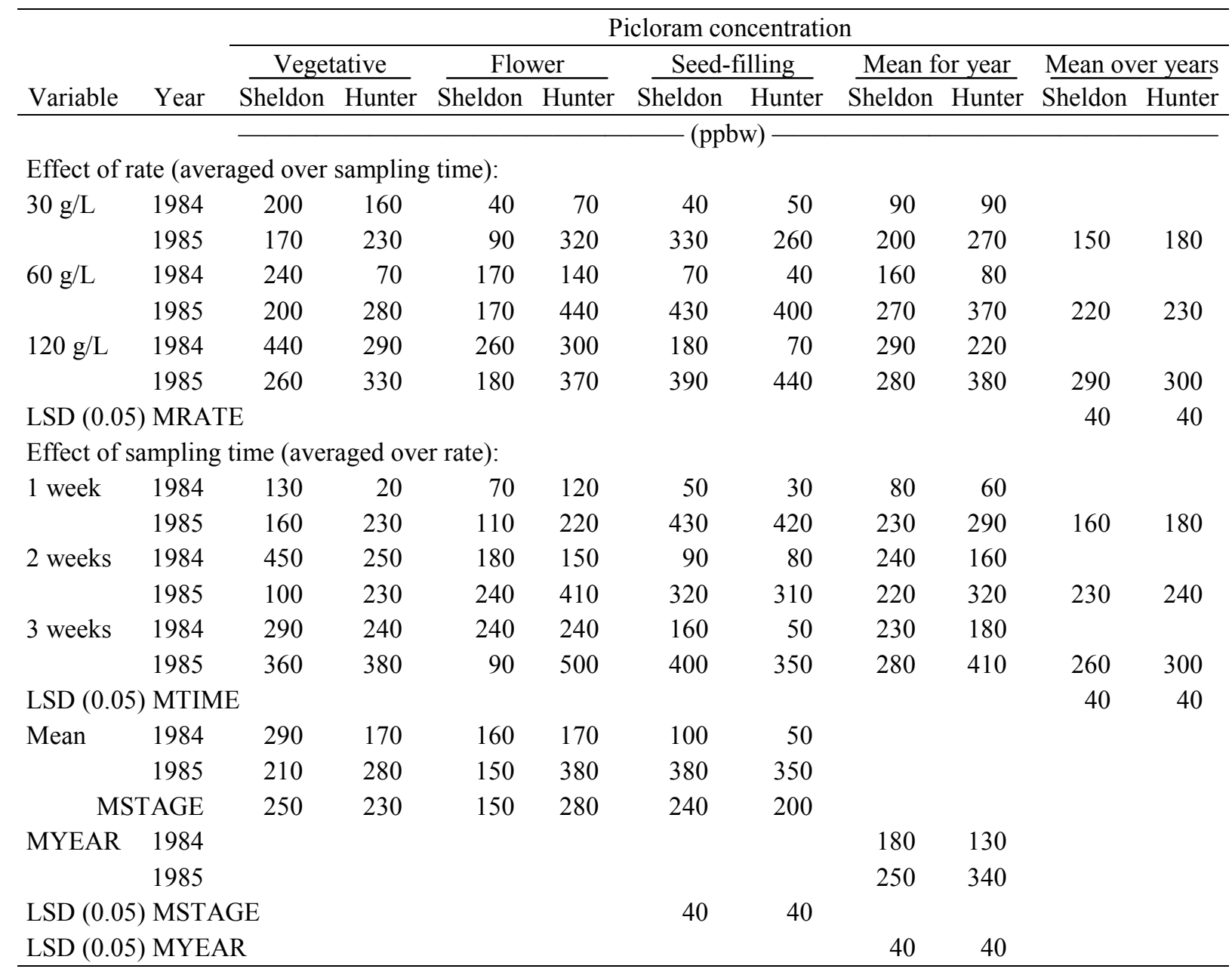

${ }^{\mathrm{a}} \mathrm{MYEAR}=$ mean year averaged over growth stage, rate, and sample time; MRATE $=$ mean rate averaged over year, growth stage, and sample time; MTIME = mean sample time averaged over year, growth stage, and rate; MSTAGE = mean growth stage averaged over year, rate, and sample time.

\section{Release 26 to $39 \mathrm{~cm}$}

Picloram residues in soil in 1984 were greatest when plants were treated in the seedfilling growth stage at Sheldon and in the vegetative and seed-filling growth stages at Hunter (Table 4). Picloram residues in 1985 were greatest for the treatments at the flowering growth stage at Hunter but there were no differences in soil residues between growth stages at Sheldon.

Release of picloram from roots, when averaged across growth stages, generally increased with application rate (Table 4). The pattern of increasing release with increasing application rate was the same for 1984 and 1985 even though no differences were detected between treatments at Hunter in 1985. 
When treatments were averaged across growth stages, soil residue levels did not significantly increase after the 2-week sampling period except at Hunter in 1985 (Table 4). Generally, picloram release from roots was greater from treatments at the flowering and seed-filling stages than from vegetative stage. This could have been due in part to greater herbicide interception by plants in the flowering and seed-filling stages compared to vegetative plants, because the more mature plants had more surface area.

The amount of picloram released from roots usually was directly correlated with the rate of application. The $120 \mathrm{~g} / \mathrm{L}$ application rate resulted in the highest average residue levels at both locations.

Release from roots occurred rapidly with $86 \%$ of the picloram detected in the 0 - to 13-cm soil depth by 1 week after application and $100 \%$ present by 2 weeks after application (Table 2). The time required for picloram residue levels in soil to reach the maximum concentration was greater for the greater sampling depths, with only $76 \%$ present in the 13- and 26-cm depth (Table 3) and 65\% present for the 26- to 39-cm depth 1 week after application (Table 4). Maximum detected residues at the deeper soil levels usually did not occur until the second or third week of sampling. This may be due to the greater distance for herbicide movement within the plant and to the reduced amount of picloram in the root because of the high rate of leakage in the upper portions of the root system.

Picloram was released at all sampling depths, but the 0 -to $13-\mathrm{cm}$ depth accounted for over $84 \%$ of the total picloram detected in soil and the two deeper levels contributed about $8 \%$ each (Tables 2, 3, and 4). This may be due to the presence of a high percentage of the plant root system in this upper portion of the soil profile (4) and to the rapid release of picloram by roots near the crown.

Coupland and Alex (4) excavated a mature stand of leafy spurge and measured $56 \%$ of the root material in the upper $15 \mathrm{~cm}$ of the soil profile. This abundance of roots resulted in a large root surface area available for herbicide leakage. An average of $62 \%$ of the root buds recovered were from this soil zone. Endogenously formed buds wound the root tissue where they erupt through the root surface, producing possible pathways for herbicide leakage. The large root surface area coupled with the root buds and associated wounding probably result in a zone of increased herbicide release.

Picloram may have been washed from the foliage to the soil by dew or precipitation between application and sampling. There was a rain shower of about $5 \mathrm{~mm}$ at Sheldon in 1984 between application and the first sampling for the vegetative growth stage, but no other precipitation was observed for any other application dates or locations in either 1984 or 1985 . This lack of precipitation minimizes the possibility of soil contamination from the herbicide washing off the foliage or from herbicide leaching with infiltrating water.

Seedlings of leafy spurge can emerge from $15 \mathrm{~cm}$, but most emerge from seed buried 1.3 to $5 \mathrm{~cm}$ deep (17). Emergence from $1 \mathrm{~cm}$ or less probably is limited by high soil temperatures and low soil moisture. Picloram soil residues of 500 ppbw reduced leafy spurge seedling emergence by $50 \%$, and soil residues of 250 ppbw reduced seedling survival by $50 \% 4$ weeks after emergence (14). Based on these results (14), picloram soil residues detected following all treatments in the present study should reduce seedling emergence and survival to less than $50 \%$. 
Table 4. Picloram concentrations in soil from 26- to 39-cm depth at Sheldon and Hunter, ND, 1, 2, and 3 weeks after treatment at three rates on vegetative, flowering, and seed-filling leafy spurge in 1984 and 1985.

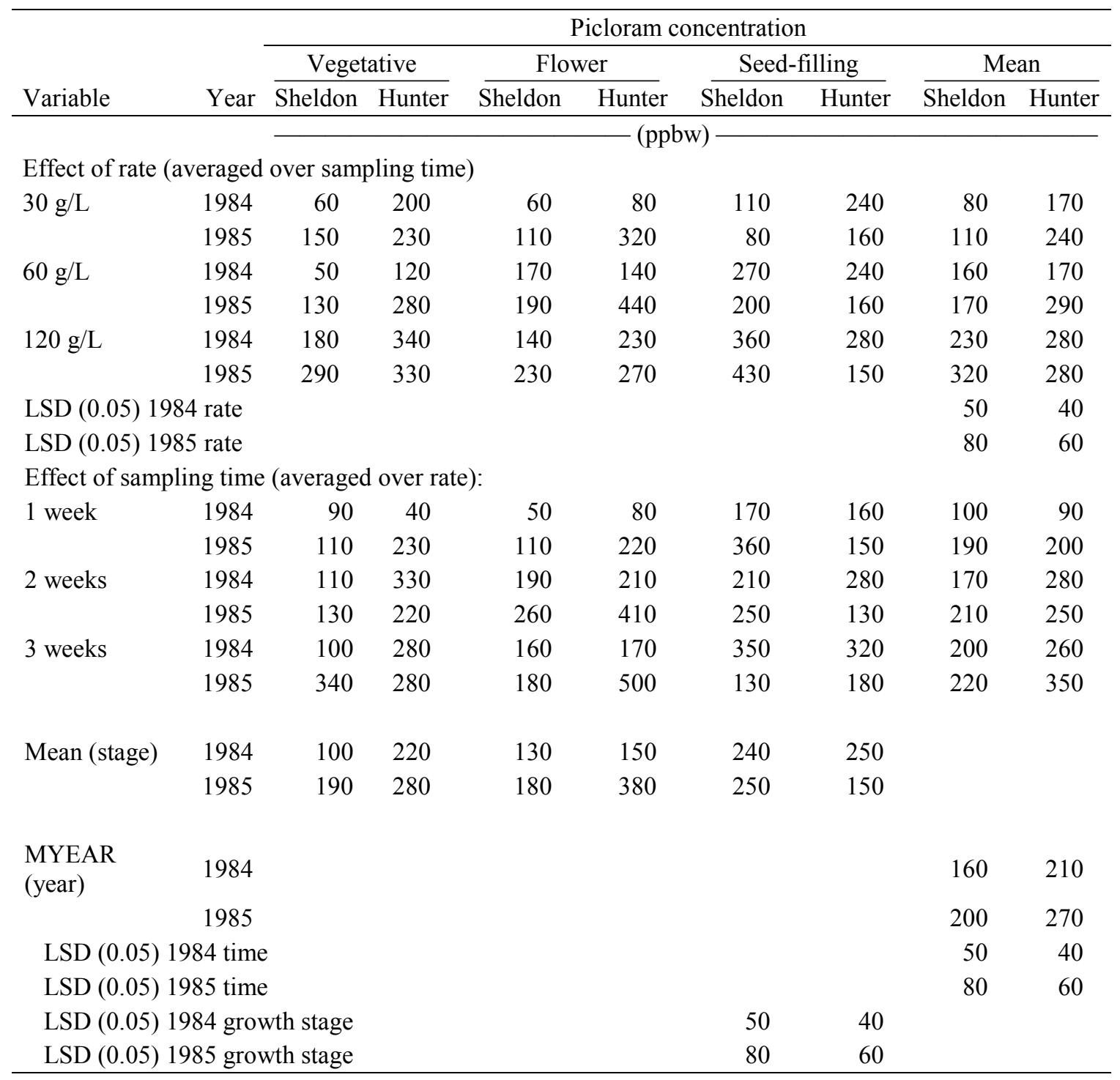

\section{Root growth inhibition}

The initial picloram concentration in soil or treatment depth had little effect on leafy spurge shoot emergence (Table 5). Over $5 \mathrm{~cm}$ of precipitation fell 48 hours following the establishment of the experiment in 1986, resulting in a rapid decline in picloram residue. (This will be discussed separately.)

Picloram at 1000 pbbw 0 to $15 \mathrm{~cm}$ deep in soil delayed emergence the longest and averaged 84 and 155 days after treatment at the experiment station and cemetery, respectively (Table 5). About $60 \mathrm{ppbw}$ picloram remained in the soil when leafy spurge emerged regardless of the original treatment rate or depth, except for the 1000 ppbw con- 
centration at the 0 - to $15-\mathrm{cm}$ depth near the cemetery which had 5 ppbw picloram remaining and was the only treatment that delayed shoot emergence until the following growing season. Leafy spurge shoots emerged within 64 days after treatment when averaged over the treatment depth and rate compared to an average of 56 days for the untreated control at the experiment station. The average difference in time to emergence between treated and untreated plants was only 13 days at the cemetery, excluding picloram at $1000 \mathrm{ppbw}$ at the 0 - to $15-\mathrm{cm}$ depth.

Table 5. Time to leafy spurge shoot emergence after picloram treatment (soil excavated and replaced with picloram-treated soil) at two depths and two locations near Fargo, ND.

\begin{tabular}{|c|c|c|c|c|c|c|c|c|c|c|}
\hline \multirow{3}{*}{$\begin{array}{l}\text { Treatment } \\
\text { depth }\end{array}$} & \multirow{3}{*}{$\begin{array}{l}\text { Picloram } \\
\text { rate }\end{array}$} & \multicolumn{3}{|c|}{ Precipitation $^{\mathrm{a}}$} & \multicolumn{3}{|c|}{ Time to emergence } & \multicolumn{3}{|c|}{ Picloram residue ${ }^{\mathrm{b}}$} \\
\hline & & \multirow{2}{*}{$\begin{array}{c}\text { Experiment } \\
\text { station } \\
1985\end{array}$} & \multicolumn{2}{|c|}{ Cemetery } & \multirow{2}{*}{$\begin{array}{c}\text { Experiment } \\
\text { station } \\
1985 \\
\end{array}$} & \multicolumn{2}{|c|}{ Cemetery } & \multirow{2}{*}{$\begin{array}{c}\text { Experiment } \\
\text { station } \\
1985 \\
\end{array}$} & \multicolumn{2}{|c|}{ Cemetery } \\
\hline & & & 1985 & 1986 & & 1985 & 1986 & & 1985 & 1986 \\
\hline$(\mathrm{cm})$ & (ppbw) & \multicolumn{3}{|c|}{$(\mathrm{cm})$} & \multicolumn{6}{|c|}{ (days) $-(\mathrm{ppbw})$} \\
\hline $0-7.5$ & 0 & 13 & 13 & 14 & 32 & 23 & 42 & ND & ND & ND \\
\hline \multirow{7}{*}{$0-15$} & 250 & 17 & 15 & 14 & 61 & 35 & 36 & 80 & 35 & ND \\
\hline & 500 & 24 & 15 & 14 & 80 & 35 & 39 & 60 & 40 & ND \\
\hline & 1000 & 15 & 17 & 14 & 40 & 65 & 43 & 60 & 50 & ND \\
\hline & 0 & 24 & 16 & 16 & 80 & 50 & 56 & ND & ND & ND \\
\hline & 250 & 17 & 17 & 16 & 66 & 60 & 56 & 60 & 40 & ND \\
\hline & 500 & 16 & 16 & 17 & 52 & 52 & 59 & 80 & 50 & ND \\
\hline & 1000 & 26 & 61 & 18 & 84 & $155^{\mathrm{c}}$ & 61 & 70 & 5 & ND \\
\hline $\operatorname{LSD}(0.05)$ & & & & & NS & 32 & 10 & 25 & 23 & NS \\
\hline
\end{tabular}

The high precipitation received following establishment of the experiment in 1986 probably resulted in considerable picloram leaching through the soil. An average of $8 \mathrm{~cm}$ precipitation leached picloram $10 \mathrm{~cm}$ in five soil types with just $5.6 \mathrm{~cm}$ required to leach picloram in Asquith sandy loam (9). Stems emerged in about 40 and 58 days from the 7and $15-\mathrm{cm}$ depths regardless of picloram concentration, which is about $25 \%$ earlier than in 1985 (Table 5). There was no detectable picloram remaining in any of the treated soil.

Picloram soil residue had little effect on preventing leafy spurge regrowth. Even a residue of 1000 ppbw 0 to 7.5 and 0 to $15 \mathrm{~cm}$ deep in the soil, which corresponds to approximately 1.1 and $2.2 \mathrm{~kg} / \mathrm{ha}$, respectively, generally delayed emergence only slightly compared to untreated soil. These results are similar to those found in growth chamber studies in which soil concentrations of at least 250 ppbw were required to inhibit growth of leafy spurge root segments (14). Thus, although picloram release from leafy spurge roots can average over 1000 ppbw, it is not likely this residue would prohibit regrowth of leafy spurge roots for more than 1 or 2 months. However, it may inhibit growth of leafy spurge seedlings and other broadleaf species. 


\section{Literature cited}

1. Bjerke, E. L. 1973. Determination of residues of picloram in soil by gas chromatography. ACR 73.3. Dow Chem. Co., Midland, MI.

2. Bybee, T. A. 1979. Factors affecting leafy spurge control including leafy spurge reestablishment, herbicide application dates, herbicide translocation and root carbohydrates. Ph.D. Thesis, North Dakota State Univ. Univ. Microfilms. Ann Arbor, MI. (Diss. Abstr. 7922217).

3. Chang, F. Y. and W. H. Vanden Born. 1968. Translocation of dicamba in Canada thistle. Weed Sci. 16:176-181.

4. Coupland, R. T. and J. F. Alex. 1955. Distribution of vegetative buds on underground parts of leafy spurge (Euphorbia esula L.). Can. J. Agric. Sci. 35:76-82.

5. Ebke, D. H. and M. K. McCarty. 1983. A nursery of leafy spurge (Euphorbia spp.) complex from North America. Weed Sci. 31:866-873.

6. Fites, R. C., F. W. Slife, and J. B. Hanson. 1964. Translocation and metabolism of radioactive 2,4-D in jimsonweed. Weeds 12:180-183.

7. Galoux, M. P., A. C. Bernes, and J. C. Van Damme. 1985. Gas chromatographic determination of 3,6dichloro-picolinic acid residues in soils and its application to the residue dissipation in a soil. J. Agric. Food Chem. 33:965-968.

8. Gomez, K. A. and A. A. Gomez. 1984. Statistical Procedures for Agricultural Research. 2nd ed. John Wiley and Sons, New York.

9. Grover, R. 1977. Mobility of dicamba, picloram, and 2,4-D in soil columns. Weed Sci. 25:159-162.

10. Hurtt, W. and C. L. Foy. 1965. Excretion of foliar-applied dicamba and picloram from roots of Black Valentine beans grown in soil, sand, and culture solution. Proc. 19th Northeast Weed Control Conf. Page 602.

11. Lingle, S. E. and J. C. Suttle. 1985. A model system for the study of 2,4-D translocation in leafy spurge. Can. J. Plant Sci. 65:369-377.

12. Lym, R. G. and C. G. Messersmith. 1983. Control of leafy spurge with herbicides. North Dakota Farm Res. 40(5):16-19.

13. Lym, R. G. and C. G. Messersmith. 1987. Carbohydrates in leafy spurge roots as influenced by environment. J. Range Manage. 40:139-144.

14. Lym, R. G. and C. G. Messersmith. 1987. Leafy spurge control and herbicide residue from annual picloram and 2,4-D applications. J. Range Manage. 40:194-198.

15. Messersmith, C. G. and R. G. Lym. 1981. A pipe-wick herbicide applicator for perennial weed control in pastures. Res. Rep. North Cent. Weed Control Conf. 38:36-37.

16. Neidermyer, R. W. and J. D. Nalewaja. 1969. Uptake, translocation and fate of 2,4-D in nightflowering catchfly and common lambsquarters. Weed Sci. 17:528-532.

17. Selleck, G. W., R. T. Coupland, and C. Frankton. 1962. Leafy spurge in Saskatchewan. Ecol. Monogr. 32:1-29.

18. Sharma, M. P. and W. H. Vanden Born. 1971. Effect of picloram on ${ }^{14} \mathrm{CO}_{2}$-fixation and translocation of ${ }^{14} \mathrm{C}$ - assimilates of Canada thistle, soybean, and corn. Can. J. Bot. 49:69-74.

19. Wells, M. J. M., J. L. Michael, and D. G. Neary. 1984. Determination of picloram in soil and water by reversed-phase liquid chromatography. Arch. Environ. Contam. Toxicol. 13:231-235. 